\title{
Addiction and the Dark Triad of Personality
}

\author{
Emanuel Jauk ${ }^{1 *}$ and Raoul Dieterich ${ }^{2}$ \\ ${ }^{1}$ Clinical Psychology and Behavioral Neuroscience, Faculty of Psychology, Technische Universität Dresden, Dresden, \\ Germany, ${ }^{2}$ Addiction Research, Faculty of Psychology, Technische Universität Dresden, Dresden, Germany
}

In this article, we review associations between the Dark Triad of personality (narcissism, Machiavellianism, and psychopathy) and addictive behaviors, both substance-related and non-substance-related. We summarize evidence from personality and clinical research and integrate it with prevailing models of addiction. Specifically, we discuss addictive behavior in the light of affect regulation, which is likely more relevant in narcissism, as well as inhibitory deficits, a putative mechanism in psychopathy. These mechanisms can be related to central motives of the respective personality constructs, such as stabilization of self-esteem in narcissism and impulsive stimulation seeking in psychopathy. We conclude that different mechanisms might lead to similar observable behavior in narcissism and psychopathy at earlier stages of the addiction cycle, but psychopathic disinhibition might be particularly relevant at later stages. This underpins the importance of considering personality factors for the understanding and treatment of addiction.

Keywords: Dark Triad, narcissism, Machiavellianism, psychopathy, substance use, substance use disorder, addiction

\section{THE DARK TRIAD}

The Dark Triad of personality_narcissism, Machiavellianism, and psychopathy (1)-attracted enormous research interest in the past decades. Given that the three traits are tied together by antagonism as a marker of emotionally cold interpersonal behavior (2), much of the pertinent literature focuses on intrinsically interpersonal topics such as workplace behavior, interpersonal attraction, or generally competitive contexts (3). The socially aversive, "dark" personality characteristics are partially related to short-term individual benefits in these contexts, such as vocational success [e.g., Ref. (4)] or mating success [e.g., Ref. (5)]. Besides these benefits, there are also significant costs. These encompass avoidant attachment [e.g., Ref. (6)]; dissatisfaction regarding needs for relatedness, competence, and autonomy; feelings of inauthenticity (7); reduced mental health $^{1}$; risk-taking behavior; and-most important for the present review-substance use $(8,9)$.

We describe contemporary models of the three traits and review their associations with addictive behavior (substance-related and non-substance-related). We adopt a dimensional perspective, which assumes that the three traits display continuous distributions bending into clinically relevant personality configurations towards the upper ends. Additionally, we highlight findings from clinical groups with substance use disorders and/or personality disorders. The amount of available literature on the three traits differs substantially, with some literature for narcissism, little for Machiavellianism, and most for psychopathy. Among the three, it is mostly narcissism and

${ }^{1}$ It needs to be noted, though, that the effects are heterogeneous for the three traits, and particularly narcissism, is also related

to reports of subjective well-being.

Triad of Personality.

Front. Psychiatry 10:662. doi: 10.3389/fpsyt.2019.00662 
psychopathy that display associations to substance use [e.g., Ref. (10), see Table 1]. Comorbidities of substance use disorders and the respective personality disorders are also well documented in community samples (11) and clinical groups $(12,13)$. The mechanisms promoting addictive behaviors in narcissism and psychopathy might differ and potentially target different phases of the addiction cycle: on the one hand, initially, instrumental use, driven by self-stabilizing motives, and on the other hand, compulsive use, characterized by loss of control despite negative consequences, which circumscribe fully developed substance use disorders (14).

\section{NARCISSISM}

Structural models of narcissism place self-importance and entitlement-both aspects of antagonism-at the core of the construct $(15,16)$. Beyond that, a grandiose form, a socially dominant, agentic-antagonistic interpersonal style, and a vulnerable form, a neurotic-antagonistic style, can be distinguished (16). In the general population, the grandiose and the vulnerable forms of narcissism are unrelated and display opposing characteristics with respect to psychological functioning and mental health, with grandiosity displaying (mostly) adaptive adjustment in self-report studies and vulnerability displaying signs of maladaptive adjustment and mental illness [cf. Ref. (17)]. Our recent studies suggest that both aspects might be intertwined at high grandiosity $(18,19)$. Concurrent grandiosity and vulnerability are referred to as pathological narcissism (20).

Grandiose narcissism is associated with substance useparticularly alcohol-in nonclinical groups (10, 21-25) and is elevated in substance use disorder groups (26). Vulnerable narcissism is also associated with substance use in nonclinical groups (21). Accordingly, pathological narcissism (concurrent grandiosity and vulnerability) was found to be substantially associated with alcohol and drug use $(27,28)$. Individuals with substance use disorders, compared to controls, display higher pathological narcissism, particularly in aspects of vulnerability such as entitlement rage, ${ }^{2}$ devaluing, hiding the self, and selfesteem contingency (30). Narcissistic personality disorder (defined as extreme grandiosity) is comorbid with alcohol and drug dependence (13). However, regarding dependence, narcissistic personality disorder does not necessarily have higher rates of comorbidity than other personality disorders (31, 32). Comorbidities might be explained by general functional impairment rather than specific characteristics of narcissism (33).

The putative mechanisms mediating substance use in narcissism are seen in self-regulatory functions, particularly the stabilization of self-esteem, which is high but instable in grandiose narcissism (34) and low in vulnerable narcissism (35). Drinking is related to grandiose narcissism and selfesteem contingency (such as need for approval) (23). Grandiose narcissism predicts drinking behavior independently of

\footnotetext{
${ }^{2}$ Entitlement rage was considered a facet of grandiosity or vulnerability in different studies [see Ref. (29)].
}

impulsivity, which indicates that other mechanisms might be relevant (24). This becomes even more apparent when grandiosity is accompanied by vulnerability, for which increased feelings of shame explain the association with problematic alcohol use (21).

Interestingly, in a recent study, an interpersonal aspect of pathological narcissism, devaluing, again turned out to be among the strongest predictors of impaired control over drinking and associated problems (36). Devaluing reflects "disinterest in others who do not provide needed admiration and shame over needing recognition from disappointing others" (37, p. 368). It could thus be speculated that this particular pattern of interpersonal avoidance goes hand in hand with substituting "real" others for "ideal" experiential states induced by the drug, such as long posited by psychoanalytic theorists: "Actually, the very term, 'drug dependency' reminds us of what we are dealing with, namely an archaic passive dependency on an all-giving, sempiternal, though narcissistically perceived-i.e., hugely inflated-object"3 (38, p. 838).

Beyond substance-related behavior, grandiose narcissism is linked to addictive social media use (24, 39-41), compulsive smartphone use (42), compulsive buying (43), pathological gambling (44), or compulsive working (45). Studies comparing grandiose narcissism to the other Dark Triad traits, however, do not always find effects for narcissism, but also point to the role of psychopathic or Machiavellian traits instead (46-49). The mechanisms that likely mediate the relationship between grandiose narcissism and problematic social media use are similar to those for substance use: grandiose narcissism is related to addictive Facebook usage via the need to be admired and-to a lesser extent-the need to belong (50). If their need for admiration is not satisfied, individuals with grandiose traits display more risk-taking behavior (51). In contrast to substance-related behavior (drinking), however, the associations between grandiose narcissism and disordered social media use can be explained by increased reward sensitivity (24), which points to the stronger involvement of approach-orientation.

Interestingly, in social anxiety disorder and avoidant personality disorder-which are highly comorbid with alcohol use disorder $(52,53)$-interpersonal coping is also a frequently encountered motive for initial drinking. This highlights further parallels between social anxiety and vulnerable narcissism, which display substantial conceptual and empirical overlaps (54). Recent evidence suggests that socially anxious individuals who develop problematic or addictive drinking patterns may belong to a highly impulsive subtype of social anxiety disorder $(55,56)$. Future research on narcissism and addiction could integrate these findings to elucidate more fine-grained predictors of problematic or addictive substance use in narcissism.

Taken together, self-regulatory mechanisms-particularly the regulation of a chronically instable self-esteem-play a major role in the relation between narcissism and addictive behavior. For substance-related behaviors, this is most evident in substance use

\footnotetext{
${ }^{3}$ The object, in psychoanalytic terms, refers to a real or imagined other, as a counterpart to the subject.
} 
to cope with negative affect due to lack of others' admiration and feelings of shame related to narcissistic vulnerability. For nonsubstance-related behaviors, using social media to feel admired might be a central mechanism.

\section{MACHIAVELLIANISM}

The concept of Machiavellianism was derived from Niccolò Machiavelli's writings by the social psychologists Richard Christie and Florence Geis (57). In their conception, individuals displaying Machiavellian tendencies are characterized by instrumental and strategic interpersonal behavior alongside low orientation towards moral standards. In the Five Factor Model framework, Machiavellianism is-like narcissism and psychopathy-primarily characterized by interpersonal antagonism (58).

Christie and Geis (57) postulated that "Machs" should be characterized by the absence of psychopathology to allow for effective reality testing. This suggests that, among the three socially aversive traits, Machiavellianism should show no associations, or even negative associations, with addictive behavior. While empirical studies are scarce, Machiavellianism is indeed not significantly associated with global indices of substance use (10). Machiavellianism is, however, higher in cocaine users (59) and positively associated with indicators of problematic or addictive internet use $(41,47,49)$, though not all studies find such associations $(46,48)$.

Beyond addictive behavior, empirical findings show that Machiavellianismis-depending on the scaleand factor structurenot generally independent of psychopathology (60). However, some of these associations might be due to the multifaceted nature of the traditional Machiavellianism inventory, which also assesses low conscientiousness $(58,61)$. Recently, a new Machiavellianism scale was designed to assess the core characteristics in a purer fashion. Machiavellianism was uncorrelated with substance use and gambling; the "planful" aspect of Machiavellianism (positively associated with conscientiousness) was even negatively related to both (61), as could be expected on the basis of the original construct definition. To sum up, while more research will be needed for a comprehensive picture, existing studies do not point to a pivotal role of Machiavellianism in substance use, but suggest some associations with problematic internet use. Results may strongly depend on the operationalization of Machiavellianism, particularly the extent to which it draws on disinhibited (lowconscientious) aspects.

\section{PSYCHOPATHY}

Structural models conceive psychopathy as a syndrome of interpersonal-affective and antisocial-deviant personality and behavior characteristics (62). These encompass, amongst others, an interpersonal style of superficial charm, grandiose self-worth (linking psychopathy to narcissism), manipulative behavior, shallow affect, and lack of empathy, as well as delinquency, stimulation seeking, and impulsivity. Regarding broad traits, psychopathy can be characterized mainly by interpersonal antagonism and aspects of low conscientiousness (disinhibition)
(63-66). Traditional models of psychopathic traits in the general population also build upon the distinction between interpersonal-affective characteristics, also called factor 1 or primary psychopathic traits, and antisocial-deviant aspects, also referred to as factor 2 or secondary psychopathic traits (67). Alternative models propose two or three factors named fearless dominance/boldness, self-centered impulsivity/disinhibition, and coldheartedness/meanness $(63,68)$.

Psychopathic traits are reliably associated with substance use and addiction in forensic populations $(12,69-71)$ and also in the general population $(10,72,73)$. The mechanisms that foster substance use and addiction in relation to psychopathic traits might differ from those of narcissism. Psychopathy-as outlined above-is associated with stimulation seeking and reduced inhibitory control with regard to potentially risky behavior [e.g., Ref. (10)]. Among the two factors, it is thus mainly the antisocialdeviant behavior, or secondary psychopathy, which is associated with substance use $(12,69,71)$.

Neuroimaging work suggests that psychopathic-particularly antisocial-deviant-traits among healthy individuals are positively associated with striatal brain activity during monetary reward anticipation and application of amphetamine $(74,75)$, even when controlling for impulsivity. Given that similarly altered brain responses can predict problematic drug involvement (76), striatal hyperreactivity might facilitate drug use in highly riskprone psychopathic individuals (but see evidence for striatal hyporeactivity as predictor of problematic drug use), (77). Drug users develop a sensitivity to substance cues, manifesting in increased activity in a circuit mediating reward, value, emotion, and salience processing, which is also related to subjective craving $(78,79)$. This is consistent with the incentive sensitization theory of addiction, which posits that pathologically high attribution of incentive salience to drug cues ("wanting/craving"), rather than the pleasurable effect of drugs ("liking"), drives compulsive drug use (80).

Interestingly, a neuroimaging study of the effects of drug cues in criminal offenders with a history of substance use disorders showed that characteristics of psychopathy negatively modulated brain responses to substance cues in this cue reactivity circuit (81). Modulation of brain responses was more pronounced for factor 2 (antisocial-deviant) than factor 1 (interpersonal-affective) psychopathy. A similar finding was recently obtained for adolescents: psychopathic characteristics negatively modulated neural cue reactivity, though in the youth sample, the negative association was more pronounced for factor 1 (82). However, most recently, a study on adult parolees with substance use disorder found evidence for a positive modulation of brain activation to drug cues by psychopathic traits (factor 1) (83). An important difference between this study and the prior investigations is the use of food cues rather than neutral stimuli as a control condition. The authors argue that individuals with higher psychopathic traits display stronger desensitization of non-drug-related cues. However, this effect was moderated by drug use history in such a way that highly psychopathic individuals with a longer drug use history showed lower sensitivity to drug cues (83). 
TABLE 1 | Summary of the reviewed literature on Dark Triad traits in relation to substance use and addictive behaviors.

\begin{tabular}{|c|c|c|c|}
\hline & Narcissism & Machiavellianism & Psychopathy \\
\hline Central characteristics & Self-importance and entitlement & $\begin{array}{l}\text { Instrumental and manipulative } \\
\text { behavior }\end{array}$ & $\begin{array}{l}\text { Interpersonal-affective and } \\
\text { antisocial-deviant traits }\end{array}$ \\
\hline Primary broad trait & Antagonism & Antagonism & Antagonism \\
\hline Secondary broad trait & $\begin{array}{l}\text { Extraversion (grandiose)/neuroticism } \\
\text { (vulnerable) }\end{array}$ & Unclear & Disinhibition (low conscientiousness) \\
\hline Associations with substance use & + & $\sim$ & ++ \\
\hline Motives for substance use & $\begin{array}{l}\text { Regulation of self-esteem (grandiose and } \\
\text { vulnerable), negative affect reduction } \\
\text { (vulnerable) }\end{array}$ & Unclear & Stimulation seeking \\
\hline $\begin{array}{l}\text { Associations with substance use } \\
\text { disorder }\end{array}$ & $\sim$ & Unclear & ++ \\
\hline $\begin{array}{l}\text { Associations with non-substance- } \\
\text { related addictive behavior }\end{array}$ & $\begin{array}{l}++ \\
\text { (Robust evidence for problematic social } \\
\text { media use) }\end{array}$ & Unclear & $\begin{array}{l}+ \\
\text { (Evidence for internet use and } \\
\text { gambling) }\end{array}$ \\
\hline
\end{tabular}

"+" indicates evidence for positive association, "++" strong evidence for positive association, " " no evidence for association.

Together, these findings suggest an interaction between psychopathic personality disposition and substance use: while those without a history of substance use display increased sensitivity to monetary and drug rewards, those with a longer history of substance use display decreased reactivity to drug cues. While it needs to be noted that these phenomena tap into different aspects of the addiction cycle, tentatively speaking, these studies suggest that cue reactivity or craving might not be the primary driving force of compulsive drug use in psychopathy. Other processes such as impulsivity or insensitivity to punishment, i.e., reduced behavioral control when assessing short-term benefits versus long-term risks or the implications of immediate negative feedback, might play a more prominent role. This would be consistent with recent longitudinal work (77) and addiction models conceptualizing compulsive drug use as the result of dysfunctional decision-making and learning processes $(84,85)$.

Psychopathic traits are also associated with non-substancerelated addictive behaviors such as problematic social media or internet use (46-49) or problematic gambling (86-88) in the general population and in select populations, such as pathological gamblers [antisocial traits (89); for trait-level meta-analysis, see Ref. (90)]. In contrast to narcissism, there is little evidence for self-esteem stabilization or psychosocial coping as a functional mechanism.

Taken together, there is robust evidence for associations of substance use and addiction with psychopathic traits not only in forensic samples but also in the general population. Interestingly, these associations reflect a historic account to the classification of "anti-" as well as "dyssocial reactions" and alcohol/substance addictions, which were both subsumed under "sociopathic personality disturbance" in the first edition of the Diagnostic and Statistical Manual of Mental Disorders (DSM) [(91); see also Ref. (92)]. Unlike narcissism, there is little evidence for drug use as affect regulation in psychopathy. This aligns with the idea that individuals with psychopathic traits experience low levels of stress and anxiety, as for instance manifest in the negative correlations with neuroticism $(64,66)$. Substance use and addiction might be more related to stimulation seeking and impulsivity.

\section{CONCLUSION}

As summarized in Table 1, narcissism and psychopathy are associated with substance-related and non-substance-related addictive behavior across nonclinical and clinical populations, whereas Machiavellianism is not. This aligns well with the view that narcissism and psychopathy can be placed on the externalizing spectrum of mental disorders alongside substance use disorders, as expressed in the Hierarchical Taxonomy of Psychopathology (HiTOP) (93). Beyond that, the HiTOP differentiates antagonistic-externalizing behavior, which characterizes narcissistic as well as antisocial traits, from disinhibitedexternalizing behavior, which characterizes substance use disorders and antisocial traits. This model thus conceives antisocial traits in closer proximity to substance use than narcissistic traits, as they are tied together by disinhibited behavior (94). While this view is supported by clinical and nonclinical studies on psychopathic traits and addictive behavior, research on narcissism suggests links with substance use as well. This is in line with meta-analytic findings demonstrating that both disinhibition (linked to psychopathy) and antagonism (linked to narcissism and psychopathy) are related to substance-use disorders (95). The mechanisms promoting addictive behavior in association with narcissism and psychopathy might differ: individuals with narcissistic traits might be primarily driven by self-regulatory goals (i.e., affect regulation, stabilization of self-esteem), whereas disinhibition might foster substance use in relation to psychopathy. These mechanisms presumably target different phases of the addiction cycle. Self-regulatory goals might play a larger role in initial stages; impulsivity might be crucia to the development of fully developed substance use disorders.

\section{AUTHOR CONTRIBUTIONS}

Both authors contributed to the conceptualization and writing of this manuscript.

\section{ACKNOWLEDGEMENT}

We acknowledge open access funding by the Publication Fund of the TU Dresden. 


\section{REFERENCES}

1. Paulhus DL, Williams KM. The Dark Triad of personality: narcissism, Machiavellianism, and psychopathy. J Res Pers (2002) 36(6):556-63. doi: 10.1016/S0092-6566(02)00505-6

2. Jones DN, Figueredo AJ. The core of darkness: uncovering the heart of the Dark Triad: the core of darkness. Eur J Pers (2013) 27(6):521-31. doi: 10.1002/per.1893

3. Dinić BM, Vujić A. Five-factor model best describes narcissistic personality inventory across different item response formats. Psychol Rep (2018) 003329411879440. doi: 10.1177/0033294118794404

4. Spurk D, Keller AC, Hirschi A. Do bad guys get ahead or fall behind? Relationships of the Dark Triad of personality with objective and subjective career success. Soc Psychol Pers Sci (2016) 7(2):113-21. doi: $10.1177 / 1948550615609735$

5. Jauk E, Neubauer AC, Mairunteregger T, Pemp S, Sieber KP, Rauthmann JF. How alluring are dark personalities? The Dark Triad and attractiveness in speed dating: the Dark Triad and speed dating. Eur J Pers (2016) 30(2):12538. doi: 10.1002/per.2040

6. Fossati A, Krueger RF, Markon KE, Borroni S, Maffei C, Somma A. The DSM-5 alternative model of personality disorders from the perspective of adult attachment: a study in community-dwelling adults. J Nerv Ment Dis (2015) 203(4):252-8. doi: 10.1097/NMD.0000000000000274

7. Kaufman SB, Yaden DB, Hyde E, Tsukayama E. The Light vs. Dark Triad of personality: contrasting two very different profiles of human nature. Front Psychol (2019) 10:1-26. doi: 10.3389/fpsyg.2019.00467

8. Gott AJ, Hetzel-Riggin MD. What did you expect? Substance use expectancies mediate the relationships between Dark Triad traits, substance use, and substance preference. Psychol Rep (2018) 121(5):831-52. doi: $10.1177 / 0033294118755094$

9. Jonason PK, Baughman HM, Carter GL, Parker P. Dorian Gray without his portrait: psychological, social, and physical health costs associated with the Dark Triad. Pers Individ Dif (2015) 78:5-13. doi: 10.1016/j. paid.2015.01.008

10. Stenason L, Vernon PA. The Dark Triad, reinforcement sensitivity and substance use. Pers Individ Dif (2016) 94:59-63. doi: 10.1016/j.paid.2016.01.010

11. Agrawal A, Narayanan G, Oltmanns TF. Personality pathology and alcohol dependence at midlife in a community sample. Pers Disord (2013) 4(1):55-61. doi: $10.1037 / \mathrm{a} 0030224$

12. Smith SS, Newman JP. Alcohol and drug abuse-dependence disorders in psychopathic and nonpsychopathic criminal offenders. J Abnorm Psychol (1990) 99(4):430-9. doi: 10.1037/0021-843X.99.4.430

13. Stinson FS, Dawson DA, Goldstein RB, Chou SP, Huang B, Smith SM, et al. Prevalence, correlates, disability, and comorbidity of DSM-IV narcissistic personality disorder: results from the wave 2 national epidemiologic survey on alcohol and related conditions. J Clin Psychiatry (2008) 69(7):1033-45. doi: 10.4088/JCP.v69n0701

14. Koob GF, Volkow ND. Neurocircuitry of addiction. Neuropsychopharmacology (2010) 35(1):217-38. doi: 10.1038/npp.2009.110

15. Krizan Z, Herlache AD. The narcissism spectrum model: a synthetic view of narcissistic personality. Pers Soc Psychol Rev (2018) 22(1):3-31. doi: $10.1177 / 1088868316685018$

16. Miller JD, Lynam DR, McCain JL, Few LR, Crego C, Widiger TA, et al. Thinking structurally about narcissism: an examination of the Five-Factor Narcissism Inventory and its components. J Pers Disord (2016) 30(1):1-18. doi: 10.1521/pedi_2015_29_177

17. Kaufman SB, Weiss B, Miller JD, Campbell WK. Clinical correlates of vulnerable and grandiose narcissism: a personality perspective. J Pers Disord (2018) 1-S10. doi: 10.1521/pedi_2018_32_384

18. Jauk E, Kaufman SB. The higher the score, the darker the core: the nonlinear association between grandiose and vulnerable narcissism. Front Psychol (2018) 9:1-14. doi: 10.3389/fpsyg.2018.01305

19. Jauk E, Weigle E, Lehmann K, Benedek M, Neubauer AC. The relationship between grandiose and vulnerable (hypersensitive) narcissism. Front Psychol (2017) 8:1-10. doi: 10.3389/fpsyg.2017.01600

20. Pincus AL, Lukowitsky MR. Pathological narcissism and narcissistic personality disorder. Annu Rev Clin Psychol (2010) 6(1):421-46. doi: 10.1146/annurev.clinpsy.121208.131215
21. Bilevicius E, Neufeld DC, Single A, Foot M, Ellery M, Keough MT, et al. Vulnerable narcissism and addiction: the mediating role of shame. Addic Behav (2019) 92:115-21. doi: 10.1016/j.addbeh.2018.12.035

22. Hill EM. The role of narcissism in health-risk and health-protective behaviors. J Health Psychol (2016) 21(9):2021-32. doi: 10.1177/1359105315569858

23. Luhtanen RK, Crocker J. Alcohol use in college students: effects of level of self-esteem, narcissism, and contingencies of self-worth. Psychol Addict Behav (2005) 19(1):99-103. doi: 10.1037/0893-164X.19.1.99

24. Lyvers M, Narayanan SS, Thorberg FA. Disordered social media use and risky drinking in young adults: differential associations with addictionlinked traits. Aust J Psychol (2019) 71:223-31 doi: 10.1111/ajpy.12236

25. MacLaren VV, Best LA. Disagreeable narcissism mediates an effect of BAS on addictive behaviors. Pers Individ Dif (2013) 55(2):101-5. doi: 10.1016/j. paid.2013.02.004

26. Carter RR, Johnson SM, Exline JJ, Post SG, Pagano ME. Addiction and "generation me": narcissistic and prosocial behaviors of adolescents with substance dependency disorder in comparison to normative adolescents. Alcohol Treat Q (2012) 30(2):163-78. doi: 10.1080/07347324.2012.663286

27. Kealy D, Ogrodniczuk JS, Rice SM, Oliffe JL. Pathological narcissism and maladaptive self-regulatory behaviours in a nationally representative sample of Canadian men. Psychiatry Res (2017) 256:156-61. doi: 10.1016/j. psychres.2017.06.009

28. Mowlaie M, Abolghasemi A, Aghababaei N. Pathological narcissism, brain behavioral systems and tendency to substance abuse: the mediating role of self-control. Pers Individ Dif (2016) 88:247-50. doi: 10.1016/j. paid.2015.09.019

29. Morf CC, Schürch E, Küfner A, Siegrist P, Vater A, Back M, et al. Expanding the nomological net of the pathological narcissism inventory: German validation and extension in a clinical inpatient sample. Assessment (2017) 24(4):419-43. doi: 10.1177/1073191115627010

30. Karakoula P, Triliva S. Narcissistic vulnerability and addiction: findings from a study of people in treatment. J Drug Issues (2016) 46(4):396-410. doi: 10.1177/0022042616659761

31. Casadio P, Olivoni D, Ferrari B, Pintori C, Speranza E, Bosi M, et al. Personality disorders in addiction outpatients: prevalence and effects on psychosocial functioning. Subst Abuse (2014) 8:17-24. doi: 10.4137/SART. S13764

32. Ronningstam E. Pathological narcissism and narcissistic personality disorder in Axis I disorders. Harv Rev Psychiatry (1996) 3(6):326-40. doi: $10.3109 / 10673229609017201$

33. Miller JD, Campbell WK, Pilkonis PA. Narcissistic personality disorder: relations with distress and functional impairment. Compr Psychiatry (2007) 48(2):170-7. doi: 10.1016/j.comppsych.2006.10.003

34. Geukes K, Nestler S, Hutteman R, Dufner M, Küfner ACP, Egloff B, et al. Puffed-up but shaky selves: state self-esteem level and variability in narcissists. Pers Soc Psychol Bull (2017) 112(5):769-86. doi: 10.1037/ pspp0000093

35. Brookes J. The effect of overt and covert narcissism on self-esteem and selfefficacy beyond self-esteem. Pers Individ Dif (2015) 85:172-5. doi: 10.1016/j. paid.2015.05.013

36. Naidu ES, Patock-Peckham JA, Ruof A, Bauman DC, Banovich P, Frohe T, et al. Narcissism and devaluing others: an exploration of impaired control over drinking as a mediating mechanism of alcohol-related problems. Pers Individ Dif (2019) 139:39-45. doi: 10.1016/j.paid.2018.10.039

37. Pincus AL, Ansell EB, Pimentel CA, Cain NM, Wright AGC, Levy KN. Initial construction and validation of the Pathological Narcissism Inventory. Psychol Assess (2009) 21(3):365-79. doi: 10.1037/a0016530

38. Wurmser L. Psychoanalytic considerations of the etiology of compulsive drug use. J Am Psychoanal Assoc (1974) 22(4):820-43. doi: 10.1177/000306517402200407

39. Andreassen CS, Pallesen S, Griffiths MD. The relationship between addictive use of social media, narcissism, and self-esteem: findings from a large national survey. Addict Behav (2017) 64:287-93. doi: 10.1016/j. addbeh.2016.03.006

40. Brailovskaia J, Margraf J, Köllner V. Addicted to Facebook? Relationship between Facebook Addiction Disorder, duration of Facebook use and narcissism in an inpatient sample. Psychiatry Res (2019) 273:52-7. doi: 10.1016/j.psychres.2019.01.016 
41. Kircaburun K, Griffiths MD. The dark side of internet: preliminary evidence for the associations of dark personality traits with specific online activities and problematic internet use. J Behav Addict (2018) 7(4):993-1003. doi: 10.1556/2006.7.2018.109

42. Ksinan AJ, Mališ J, Vazsonyi AT. Swiping away the moments that make up a dull day: narcissism, boredom, and compulsive smartphone use. Curr Psychol (2019) doi: 10.1007/s12144-019-00228-7

43. Rose P. The happy and unhappy faces of narcissism. Pers Individ Dif (2002) 33(3):379-91. doi: 10.1016/S0191-8869(01)00162-3

44. Lakey CE, Rose P, Campbell WK, Goodie AS. Probing the link between narcissism and gambling: the mediating role of judgment and decisionmaking biases. J Behav Decis Mak (2008) 21(2):113-37. doi: 10.1002/bdm.582

45. Clark MA, Lelchook AM, Taylor ML. Beyond the Big Five: how narcissism, perfectionism, and dispositional affect relate to workaholism. Pers Individ Dif (2010) 48(7):786-91. doi: 10.1016/j.paid.2010.01.013

46. Chung KL, Morshidi I, Yoong LC, Thian KN. The role of the dark tetrad and impulsivity in social media addiction: findings from Malaysia. Pers Individ $\operatorname{Dif}$ (2019) 143:62-7. doi: 10.1016/j.paid.2019.02.016

47. Demircioğlu ZI, Göncü Köse A. Effects of attachment styles, dark triad, rejection sensitivity, and relationship satisfaction on social media addiction: a mediated model. Curr Psychol (2018) doi: 10.1007/s12144-018-9956-x

48. Lee S-L. Predicting SNS addiction with the Big Five and the Dark Triad. Cyberpsychology (2019) 13(1). doi: 10.5817/CP2019-1-3

49. Sindermann C, Sariyska R, Lachmann B, Brand M, Montag C. Associations between the dark triad of personality and unspecified/specific forms of Internet-use disorder. J Behav Addict (2018) 7(4):985-92. doi: 10.1556/2006.7.2018.114

50. Casale S, Fioravanti G. Why narcissists are at risk for developing Facebook addiction: the need to be admired and the need to belong. Addict Behav (2018) 76:312-8. doi: 10.1016/j.addbeh.2017.08.038

51. Crysel LC, Crosier BS, Webster GD. The Dark Triad and risk behavior. Pers Individ Dif (2013) 54(1):35-40. doi: 10.1016/j.paid.2012.07.029

52. Dimaggio G, D’Urzo M, Pasinetti M, Salvatore G, Lysaker PH, Catania D, et al. Metacognitive interpersonal therapy for co-occurrent avoidant personality disorder and substance abuse: avoidant personality disorders and addiction. J Clin Psychol (2015) 71(2):157-66. doi: 10.1002/jclp.22151

53. Schneier FR, Foose TE, Hasin DS, Heimberg RG, Liu S-M, Grant BF, et al. Social anxiety disorder and alcohol use disorder co-morbidity in the National Epidemiologic Survey on Alcohol and Related Conditions. Psychol Med (2010) 40(6):977-88. doi: 10.1017/S0033291709991231

54. Dickinson KA, Pincus AL. Interpersonal analysis of grandiose and vulnerable narcissism. J Pers Disord (2003) 17(3):188-207. doi: 10.1521/ pedi.17.3.188.22146

55. Adams T, Rapinda KK, Frohlich JR, O'Connor RM, Keough MT. Impulsivity moderates the effect of social anxiety on in-lab alcohol craving. Addict Behav (2019) 97:70-6. doi: 10.1016/j.addbeh.2019.05.025

56. Nicholls J, Staiger PK, Williams JS, Richardson B, Kambouropoulos N. When social anxiety co-occurs with substance use: does an impulsive social anxiety subtype explain this unexpected relationship? Psychiatry Res (2014) 220(3):909-14. doi: 10.1016/j.psychres.2014.08.040

57. Christie R, Geis FL. Studies in Machiavellianism. New York: Academic Press. (1970). doi: 10.1016/C2013-0-10497-7

58. Lee K, Ashton MC. Psychopathy, Machiavellianism, and narcissism in the Five-Factor Model and the HEXACO model of personality structure. Pers Individ Dif (2005) 38(7):1571-82. doi: 10.1016/j.paid.2004.09.016

59. Quednow BB, Hulka LM, Preller KH, Baumgartner MR, Eisenegger C, Vonmoos M. Stable self-serving personality traits in recreational and ependent cocaine users. PLoS One (2017) 12(3):e0172853. doi: 10.1371/ journal.pone. 0172853

60. Monaghan C, Bizumic B, Sellbom M. The role of Machiavellian views and tactics in psychopathology. Pers Individ Dif (2016) 94:72-81. doi: 10.1016/j. paid.2016.01.002

61. Collison KL, Vize CE, Miller JD, Lynam DR. Development and preliminary validation of a five factor model measure of Machiavellianism. Psychol Assess (2018) 30(10):1401-7. doi: 10.1037/pas0000637

62. Hare RD, Neumann CS. Psychopathy as a clinical and empirical construct. Annu Rev Clin Psychol (2008) 4(1):217-46. doi: 10.1146/annurev. clinpsy.3.022806.091452
63. Lilienfeld SO, Watts AL, Francis Smith S, Berg JM, Latzman RD. Psychopathy deconstructed and reconstructed: identifying and assembling the personality building blocks of Cleckley's chimera: psychopathy deconstructed. J Pers (2015) 83(6):593-610. doi: 10.1111/jopy.12118

64. Miller JD, Lynam DR. Psychopathy and the five-factor model of personality: a replication and extension. J Pers Assess (2003) 81(2):168-78. doi: 10.1207/ S15327752JPA8102_08

65. Miller JD, Lynam DR. Psychopathy and personality: advances and debates: psychopathy and personality. JPers (2015) 83(6):585-92. doi: 10.1111/jopy.12145

66. Miller JD, Lynam DR, Widiger TA, Leukefeld C. Personality disorders as extreme variants of common personality dimensions: can the five factor model adequately represent psychopathy? J Pers (2001) 69(2):253-76. doi: 10.1111/1467-6494.00144

67. Levenson MR, Kiehl KA, Fitzpatrick CM. Assessing psychopathic attributes in a noninstitutionalized population. Pers Soc Psychol Bull (1995) 68(1):1518. doi: 10.1037/0022-3514.68.1.151

68. Patrick CJ, Drislane LE. Triarchic model of psychopathy: origins, operationalizations, and observed linkages with personality and general psychopathology: triarchic model of psychopathy. J Pers (2015) 83(6):62743. doi: 10.1111 /jopy. 12119

69. Hemphill JF, Hart SD, Hare RD. Psychopathy and substance use. J Pers Disord (1994) 8(3):169-80. doi: 10.1521/pedi.1994.8.3.169

70. Hopley AAB, Brunelle C. Personality mediators of psychopathy and substance dependence in male offenders. Addict Behav (2012) 37(8):947-55. doi: 10.1016/j.addbeh.2012.03.031

71. Walsh Z, Allen LC, Kosson DS. Beyond social deviance: substance use disorders and the dimensions of psychopathy. J Pers Disord (2007) 21(3):273-88. doi: 10.1521/pedi.2007.21.3.273

72. Sellbom M, Donnelly KM, Rock RC, Phillips TR, Ben-Porath YS. Examining gender as moderating the association between psychopathy and substance abuse. Psychol Crime Law (2017) 23(4):376-90. doi: 10.1080/1068316X.2016.1258466

73. Fernández D, Zabala MC, Ros L, Martínez M, Martínez A, Latorre JM, et al. Testing the properties of the triarchic model of psychopathy in a community sample: self-reported trait aggression and drug consumption associations. Scand J Psychol (2019) 60(4):377-85. doi: 10.1111/sjop.12542

74. Bjork JM, Chen G, Hommer DW. Psychopathic tendencies and mesolimbic recruitment by cues for instrumental and passively obtained rewards. Biol Psychol (2012) 89(2):408-15. doi: 10.1016/j.biopsycho.2011.12.003

75. Buckholtz JW, Treadway MT, Cowan RL, Woodward ND, Benning SD, Li R, et al. Mesolimbic dopamine reward system hypersensitivity in individuals with psychopathic traits. Nat Neurosci (2010) 13(4):419-21. doi: 10.1038/ nn. 2510

76. Heitzeg MM, Villafuerte S, Weiland BJ, Enoch M-A, Burmeister M, Zubieta J-K, et al. Effect of GABRA2 genotype on development of incentive-motivation circuitry in a sample enriched for alcoholism risk. Neuropsychopharmacology (2014) 39(13):3077-86. doi: 10.1038/npp.2014.161

77. Büchel C, Peters J, Banaschewski T, Bokde ALW, Bromberg U, Conrod PJ, et al. Blunted ventral striatal responses to anticipated rewards foreshadow problematic drug use in novelty-seeking adolescents. Nat Commun (2017) 8(1):14140. doi: $10.1038 /$ ncomms14140

78. Kühn S, Gallinat J. Common biology of craving across legal and illegal drugs-a quantitative meta-analysis of cue-reactivity brain response: common biology of craving across legal and illegal drugs. Eur J Neurosci (2011) 33(7):1318-26. doi: 10.1111/j.1460-9568.2010.07590.x

79. Noori HR, Cosa Linan A, Spanagel R. Largely overlapping neuronal substrates of reactivity to drug, gambling, food and sexual cues: a comprehensive metaanalysis. Eur Neuropsychopharmacol (2016) 26(9):1419-30. doi: 10.1016/j. euroneuro.2016.06.013

80. Robinson TE, Berridge KC. The neural basis of drug craving: an incentivesensitization theory of addiction. Brain Res Rev (1993) 18(3):247-91. doi: 10.1016/0165-0173(93)90013-P

81. Cope LM, Vincent GM, Jobelius JL, Nyalakanti PK, Calhoun VD, Kiehl KA. Psychopathic traits modulate brain responses to drug cues in incarcerated offenders. Front Hum Neurosci (2014) 8:1-16. doi: 10.3389/ fnhum.2014.00087

82. Vincent GM, Cope LM, King J, Nyalakanti P, Kiehl KA. Callousunemotional traits modulate brain drug craving response in high-risk young 
offenders. J Abnorm Child Psychol (2018) 46(5):993-1009. doi: 10.1007/ s10802-017-0364-8

83. Denomme WJ, Simard I, Shane MS. Neuroimaging metrics of drug and food processing in cocaine-dependence, as a function of psychopathic traits and substance use severity. Front Hum Neurosci (2018) 12:1-13. doi: 10.3389/ fnhum.2018.00350

84. Bickel WK, Marsch LA. Toward a behavioral economic understanding of drug dependence: delay discounting processes. Addiction (2001) 96(1):7386. doi: $10.1046 / j .1360-0443.2001 .961736 . x$

85. Everitt BJ, Robbins TW. Drug addiction: updating actions to habits to compulsions ten years on. Annu Rev Psychol (2016) 67(1):23-50. doi: 10.1146/annurev-psych-122414-033457

86. Mishra S, Lalumière ML, Williams RJ. Gambling, risk-taking, and antisocial behavior: a replication study supporting the generality of deviance. J Gambl Stud (2017) 33(1):15-36. doi: 10.1007/s10899-016-9608-8

87. Onyedire NG, JohnBosco CC, Tochukwu CO, Desmond UO, Chiagoziem IA, Chuka MI. Associations of Dark Triad traits and problem gambling: moderating role of age among university students. Curr Psychol (2019) 12. doi: 0.1007/s12144-018-0093-3

88. Trombly DRC, Zeigler-Hill V. The Dark Triad and disordered gambling. Curr Psychol (2017) 36(4):740-6. doi: 10.1007/s12144-016-9461-z

89. Pietrzak RH, Petry NM. Antisocial personality disorder is associated with increased severity of gambling, medical, drug and psychiatric problems among treatment-seeking pathological gamblers. Addiction (2005) 100(8):1183-93. doi: 10.1111/j.1360-0443.2005.01151.x

90. MacLaren VV, Fugelsang JA, Harrigan KA, Dixon MJ. The personality of pathological gamblers: a meta-analysis. Clin Psychol Rev (2011) 31(6):1057-67. doi: $10.1016 /$ j.cpr.2011.02.002
91. American Psychiatric Association. Diagnostic and statistical manual of mental disorders. Washington: American Psychiatric Association (1952).

92. Crego C, Widiger TA. Psychopathy and the DSM. J Pers (2015) 83(6):665-77. doi: 10.1111 /jopy.12115

93. Kotov R, Krueger RF, Watson D, Achenbach TM, Althoff RR, Bagby RM, et al. The Hierarchical Taxonomy of Psychopathology (HiTOP): a dimensional alternative to traditional nosologies. J Abnorm Psychol (2017) 126(4):454-77. doi: 10.1037/abn0000258

94. Ruiz MA, Pincus AL, Schinka JA. Externalizing pathology and the Five-Factor Model: a meta-analysis of personality traits associated with antisocial personality disorder, substance use disorder, and their co-occurrence. J Pers Disord (2008) 22(4):365-88. doi: 10.1521/ pedi.2008.22.4.365

95. Kotov R, Gamez W, Schmidt F, Watson D. Linking "big" personality traits to anxiety, depressive, and substance use disorders: a meta-analysis. Psychol Bull (2010) 136(5):768-821. doi: 10.1037/a0020327

Conflict of Interest Statement: The authors declare that the research was conducted in the absence of any commercial or financial relationships that could be construed as a potential conflict of interest.

Copyright (๑) 2019 Jauk and Dieterich. This is an open-access article distributed under the terms of the Creative Commons Attribution License (CC BY). The use, distribution or reproduction in other forums is permitted, provided the original author(s) and the copyright owner(s) are credited and that the original publication in this journal is cited, in accordance with accepted academic practice. No use, distribution or reproduction is permitted which does not comply with these terms. 